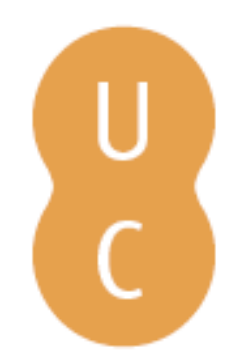

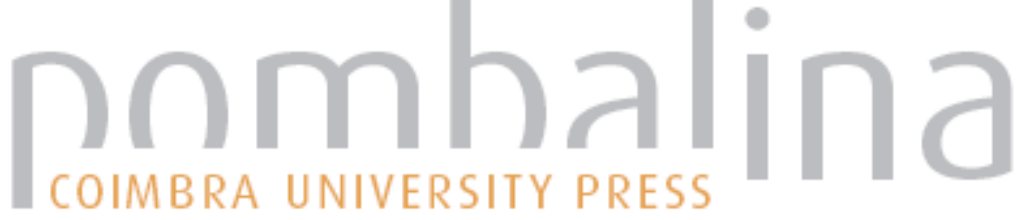

\section{A primeira historiografia da indústria portuguesa (1881-1930): uma síntese}

Autor(es): $\quad$ Rodrigues, Manuel Ferreira

Publicado por: Imprensa da Universidade de Coimbra

URL

persistente:

URI:http://hdl.handle.net/10316.2/38586

DOI:

DOI:http://dx.doi.org/10.14195/978-989-26-0646-0_15

Accessed : $\quad$ 26-Apr-2023 11:41:41

A navegação consulta e descarregamento dos títulos inseridos nas Bibliotecas Digitais UC Digitalis, UC Pombalina e UC Impactum, pressupõem a aceitação plena e sem reservas dos Termos e Condições de Uso destas Bibliotecas Digitais, disponíveis em https://digitalis.uc.pt/pt-pt/termos.

Conforme exposto nos referidos Termos e Condições de Uso, o descarregamento de títulos de acesso restrito requer uma licença válida de autorização devendo o utilizador aceder ao(s) documento(s) a partir de um endereço de IP da instituição detentora da supramencionada licença.

Ao utilizador é apenas permitido o descarregamento para uso pessoal, pelo que o emprego do(s) título(s) descarregado(s) para outro fim, designadamente comercial, carece de autorização do respetivo autor ou editor da obra.

Na medida em que todas as obras da UC Digitalis se encontram protegidas pelo Código do Direito de Autor e Direitos Conexos e demais legislação aplicável, toda a cópia, parcial ou total, deste documento, nos casos em que é legalmente admitida, deverá conter ou fazer-se acompanhar por este aviso. 


\section{A PRIMEIRA HiSTORIOGRAFIA \\ da Indústria Portuguesa (1881-1930). \\ UMA SÍNTESE}

MANUEL FERreira RodrigueS

Reunir, catalogar por assim dizer, todos os aspetos e memórias da nossa vitalidade industrial, que se acham dispersos pelos livros e documentos, quer-nos parecer que é uma empresa patriótica

(Sousa Viterbo, 1892)

\section{Autores, textos e contextos}

Uma vez que para a utopia romântica, de caráter retrospetivo, o horizonte ideológico era a ressurreição da alma nacional, apenas uma história era possível: a história da pátria, a história do génio da Nação, uma história vocacionada para «inspirar a ação política e reforçar o consenso nacional» (Catroga, 1993: 550). Desse modo, a atração pela Idade Média, tida como Idade do Ouro, como «época da robustez moral da nação» (Herculano, 1886: 134), como «cadinho das liberdades burguesas, núcleo da nobreza de caráter e da honra, origem de guerreiros ilustres e da índole portuguesa" (Ferreira, s.d.: 96), morigeradora de um presente tido como decadente, vai conduzir a geração de Herculano e Garrett (e as dos seus discípulos diretos) a um desinteresse por uma história recente, se excetuarmos alguma literatura com preocupações sociais e uma "historiografia da atualidade", mais de natureza 
política, que surgiu, como refere Fernando Catroga (1993: 549 e 557), «ideologicamente interessada em analisar ou em carrear informações que pudessem servir de ponto de partida para a explicação e legitimação histórica do novo regime». Mesmo na literatura da primeira metade de Oitocentos, como diz Alberto Ferreira (op. cit.: 99), «não é possível pensar em poesia do quotidiano (Cesário), nem em capacidade inspiradora do progresso material (Guilherme de Azevedo)».

De certo modo, esse programa historicista estrutura, também, a História de Portugal nos séculos XVII e XVIII (1860-1871) de Rebelo da Silva, discípulo confesso de Herculano. Ao valorizar o século XVII e a Restauração - entendida como uma refundação da pátria -, Rebelo da Silva parte de alguns dos pressupostos ideológicos e epistemológicos anteriores, que sustentavam o apego do primeiro romantismo à Idade Média (Macedo, 1971; Catroga, 1985 e Torgal, 1989). A divergência é protagonizada pela "geração nova". Os homens da Geração de 70, com destaque para Antero e Oliveira Martins, divergiram de Herculano na forma como olhavam a Idade Média, não escondendo o seu fascínio pela Renascença e pelos Descobrimentos (Catroga, 1982: 31). Nesse contexto, seria muito difícil a emergência de uma historiografia da indústria, mesmo que perseguisse, justificadamente, o fim último da historiografia herculaniana.

As importantes comemorações camonianas (1880) e pombalinas (1882), os inquéritos industriais de 1881 e de 1890 , as sonhadas reformas do ensino industrial (de 1884 e 1888), as exposições distritais (Aveiro, 1882; Guimarães e Coimbra, 1884), a conjuntura internacional e os seus efeitos no nosso país, testemunham, especialmente após a grave crise de 1890-1892, um olhar diferente sobre o presente e sobre o passado. De resto, a industrialização do final de Oitocentos vai desempenhar um papel decisivo nessa mudança. Como salientam Leonor Freire Costa et al. (2011: 313) «a característica mais importante do desenvolvimento da economia portuguesa ao longo do século XIX foi a sua progressiva, embora lenta, industrialização", pois "O setor industrial passou de $13 \%$ do produto interno bruto, em 1850 , para cerca de $27 \%$, em 1910 ". No entanto, não obstante o produto industrial ter crescido "cerca de 2,6\% ao ano, quando o setor agrário cresceu apenas à taxa de $0,7 \%$, «a industrialização da economia acabou por não ser suficiente para recuperar do atraso 
relativamente aos países mais industrializados da Europa" (ibidem), acabando, desse modo, por alimentar os discursos decadentistas finisseculares.

A primeira historiografia da indústria portuguesa nasce num contexto, primeiro, de crítica e, depois, de crise do liberalismo, e encontra algumas das suas referências matriciais em autores mais conotados com a defesa da industrialização e da modernização de Portugal do que pelo seu labor historiográfico, como Acúrsio das Neves (1766-1834), Oliveira Marreca (1805-1889), Pereira Caldas (1818-1903), Fradesso da Silveira (1825-1875), Brito Aranha (1833-1914), Gerardo Augusto Pery (1835-1893), e, de outro modo, Oliveira Martins (1845-1894) e Teófilo Braga (1843-1924). Essa historiografia dá os primeiros passos na década de 1880 , no quadro da crescente importância que a indústria adquire nas estratégias e nos discursos políticos, sob pressão dos ecos da industrialização europeia e das exposições mundiais da indústria.

O nacionalismo constitui, sobretudo a partir do trauma de 1890-1891, uma avassaladora força centrípeta. A nascente historiografia da indústria não ficou indiferente a esse fenómeno. Todavia, penso que existe uma interrelação complexa e indeterminada entre textos e contextos, isto é, se as conjunturas modelaram o olhar e o discurso desta historiografia, ela constitui, outrossim, um elemento fortemente estruturador desse contexto, pelas suas caraterísticas perlocutivas, porque alguns dos seus autores se assumiam e eram aceites como clercs da nova sociedade. Esses textos, bem como os seus subscritores, pelas suas singularidades biográficas, como pela sua diversidade prosopográfica, parecem constituir parte significativa dos traços estruturais do período considerado. A situação política, económica e social, o relacionamento entre centros e periferias, os mecanismos de produção, difusão e receção das ideias, a topografia social e geográfica dos historiadores estudados, constituem, por certo, um amplexo de fenómenos que se conexionam de forma diversa, alheia a qualquer tipo de univocidade ou determinação. Por essa razão, só em conjunto os textos estudados ganham sentido e permitem perceber as suas virtudes e debilidades individuais. A historiografia, como forma cultural e expressão sociocultural de uma época, regista como um sismógrafo as grandes convulsões da sociedade; quando o não faz de forma explícita, fá-lo pela omissão, pelo silêncio. A este propósito, E. H. Carr é categórico: «Não existe indicador mais significativo do 
caráter de uma sociedade do que o tipo de história que se escreve ou não consegue escrever»(Carr, 1986: 37).

Entre 1881 e 1930, foi possível reunir seis dezenas de estudos sobre história da indústria, assinados por 25 autores. Estes números devem ser entendidos de forma lata, mais como uma amostra da produção historiográfica de uma época do que um inventário, como, de resto, tive de proceder em relação ao conceito de indústria que, nesta época, é bastante imprecisa (Rodrigues, 1993). Assim, é possível discordar da inclusão de alguns textos, como os que seriam mais facilmente catalogados como história da arte, ou os extensos inventários de nomes de artífices perdidos na documentação de arquivo, ou, ainda, os estudos de Lobo d'Ávila, Fernando Emídio da Silva ou Campos Lima, como se poderá estranhar não ter considerado estudos como os de João Gomes de Oliveira Guimarães (1886), Ramalho Ortigão (1891), António Augusto Gonçalves (1898), João Faustino Nazoni da Costa (s. d.), ou o de H. P. Taveira (1923), indicados na bibliografia. De fora ficou a análise das conceções historiográficas do Boletim do Trabalbo Industrial (1906-1939) que, não obstante ter destacado os contributos de José de Oliveira Simões e de Aníbal Ferreira Cabido, merece tratamento autónomo, ou os muitos artigos e entradas sobre empresas, empresários, técnicos e operários, publicados nos dicionários e obras coletivas deste período - com destaque para o Dicionário de Esteves Pereira e Guilherme Rodrigues -, cujo inventário e estudo continuam por fazer.

Os textos reunidos apresentam a seguinte distribuição, por décadas: 18811890: 10; 1891-1900: 10; 1901-1910: 13; 1911-1920: 15; e 1921-1930: 13 estudos. A temática mais frequente é a cerâmica artística (olaria, louça e azulejos), mas marcante é a diversidade, incluindo têxteis, tapeçaria, tinturaria, papel, vidro, cristal, metais, fundição, ourivesaria, armas, moagem, marcenaria, calçado, etc. O que Carlos da Fonseca diz sobre Esteves Pereira em boa medida poderia ser dito sobre muitos destes estudiosos: «A atividade investigadora de Esteves Pereira é duma fertilidade extraordinária. Entre monografias, artigos, ou simples apontamentos, engloba as indústrias de palitos, rocas, alfinetes, móveis, sabão, fósforos, penas de escrever, gravatas, papel, vidro, azulejos, porcelana, lanifícios, chapéus, etc. [...]»(Fonseca, 1979).

Estes textos foram inicialmente publicados em jornais - esta é outra das razões da sua difícil contabilização -, revistas, catálogos de exposições, 
relatórios, etc., ou apresentados perante públicos alargados, em palestras e conferências, ou em relatórios setoriais, realizados por iniciativa própria, por determinação governamental, a pedido de associações, clubes, etc. A sua cronologia está em estreita relação com os calendários de feiras e exposições industriais, de impacte nacional ou regional, e com a crescente importância do conhecimento estatístico de Portugal. Importava estudar estes escritos em conexão com esses eventos, como convinha ver de que modo constituem instrumentos de identidade local ou regional. A sua compilação e posterior publicação na forma de livros ou de pequenas brochuras decorrem de outro tipo de fenómenos, a que não é alheia, certamente, a emergência de novas elites e a afirmação de alguns espaços municipais ou regionais. São trabalhos individuais - apenas dois resultaram de uma parceria -, embora os seus autores se conhecessem pessoalmente e publicassem conjuntamente em revistas que fundaram ou dirigiram.

Pela sua natureza, muitos destes estudos inscrevem-se numa história local, mais devedora do magistério de Herculano que de uma ideologia regionalista difusa. O «velho» Mestre sonhava com uma «história local», elaborada em «normas uniformes" de modo que um dia se pudesse "formar um grande e amplo repositório", "uma fonte de abundantes materiais para se reconstruir a história pátria», um "monumento" que perpetuasse "a vida e a finalidade da nossa gloriosa Nação" (apud Mendes, 1993: 176).

Não sendo estudos de história da indústria como a concebemos hoje - nem a disciplina possuía estatuto autónomo -, os seus autores raramente eram referidos como historiadores. O mesmo se poderia dizer da História Económica e dos seus cultores. Adriano Antero (1907:7), irritado com a confusão entre História Económica e Economia Política, recusando o epíteto de "economista», retorquia: «não somos economista, somos apenas um humilde historiador».

Ao contrário das gerações anteriores, maioritariamente formadas na Universidade de Coimbra, os historiadores recenseados têm uma formação académica muito diversificada: saíram também dos institutos industriais e comerciais, do Curso Superior de Letras, de escolas superiores de artes, medicina, ou de engenharia, portuguesas ou estrangeiras. Há-os mesmo sem formação superior, como Marques Gomes ou Joaquim Barosa. São médicos, advogados, engenheiros, gestores, jornalistas, padres, militares, bibliotecários, 
funcionários públicos, etc. Todos autodidatas, no tocante à história das atividades transformadoras, artesanais ou industriais. Por isso, a sua intervenção cultural é, no conjunto, igualmente diversificada. A par da atividade profissional, estes autores dedicaram-se à tradução, ao romance, à critica de arte, ao colecionismo (de natureza patriótica e científica), e até nos domínios da poesia e da ficção romanesca, ou teatral, deixaram marca assinalável.

$\mathrm{Na}$ investigação histórica cultivaram, a par da temática industrial (com interesse esmagador pelas atividades oficinais), a arqueologia, a história dos Descobrimentos, a história das corporações e ofícios, a diplomática, a epigrafia, a etnografia, a numismática, a biografia e a genealogia, mas, também, a história da música, a história da mulher e a história económica, a história das festas, dos usos e costumes, a história do movimento operário, chamando a atenção para o lamentável estado em que se encontravam os arquivos, nomeadamente os municipais, e para a necessidade de se valorizar o ensino industrial.

Os historiadores das duas primeiras décadas pertencem, sob diversos pontos de vista, à Geração de 70. Não espantará, assim, o predomínio das conceções organicistas, evolucionistas e transformistas. O organicismo krausiano, inimigo do liberalismo como do socialismo, defendendo a livre associação como panaceia para a solução do conflito capital-trabalho, pugnando por um Estado-árbitro de múltiplas atividades federadas, segundo o princípio da harmonia, parece constituir justificação bastante para o alheamento do emergente mundo da Fábrica. Explicar-se-ia, assim, a escassez de olhares sobre o «interior» das fábricas, sobre produção, tecnologia, operários, acidentes de trabalho, greves, etc. Alguns textos do Boletim do Trabalho Industrial e os estudos de Emídio da Silva, Lobo d'Ávila e Campos Lima revelam uma tímida mudança de atitude, mas já então se fazia sentir a influência das correntes neorromânticas do final de Oitocentos e início de Novecentos (Pereira, 1983: 845).

Nos primeiros anos da I República, os estudos históricos mostram uma maior preocupação com os problemas sociais e políticos decorrentes da implantação do novo regime e dos efeitos da Guerra. Nos anos 20, surgem trabalhos de uma enorme variedade, quando a exaltação nacionalista se aproxima do paroxismo. Os lugares comuns do historicismo oitocentista servem então, cada vez mais, desígnios de natureza antiparlamentar, antipartidária e antiurbana. Surgem as primeiras reações contra esses paladinos da glorificação 
nacionalista da História, enquanto se desenvolvem estudos etnográficos e histórias locais de cariz «bairrista». É notório um empobrecimento ao nível das fontes, da metodologia, como da teorização.

Entre os 25 nomes inventariados (ver Quadro anexo), três merecem destaque, pela inovação e pelo pioneirismo em muitos domínios do imenso e probo labor que nos legaram: Joaquim de Vasconcelos, Sousa Viterbo e Esteves Pereira.

É consensual a importância do contributo de Joaquim de Vasconcelos para a História da Arte em Portugal (românico, artes decorativas, torêutica nacional, etc.), como são reconhecidos os méritos da sua atividade como arqueólogo, etnólogo, filólogo, historiador da música e da literatura, mas raramente é reconhecida a importância do seu contributo para a história da indústria, nos domínios dos tecidos, cerâmica, vidro, mobiliário, tipografia e metalurgia, se excetuarmos a referência encomiástica ao seu envolvimento na criação e realização do Museu Industrial e Comercial do Porto, de que foi conservador (Gomes, 1978: 164 e 168). O Museu proporcionou-lhe contactos com o mundo empresarial do Norte de Portugal, levando-o a participar no debate sobre a questão pautal, muito embora defendesse as indústrias populares. Bate-se pela "verdade histórica», contra o "excesso de patriotismo dos seus confrades, expressando um nacionalismo heterodoxo que confere sentido, coerência e unidade ao seu discurso historiográfico.

A atenção que Sousa Viterbo dedica à dimensão técnica dos fenómenos faz dele quase uma exceção no ambiente cultural de generalizada misotecnia. Visando uma completa compreensão dos fenómenos históricos, o seu olhar detém-se nos pormenores técnicos, analisa as características formais, técnicas e materiais dos artefactos, sejam edifícios, máquinas, armas ou utensílios, como atribui um valor testemunhal e patrimonial aos vestígios arqueológicos, contra a corrente que viria a fazer do documento escrito matéria exclusiva da construção historiográfica. Viterbo é um dos primeiros a usar a expressão Arqueologia Industrial, embora esta disciplina seja hoje diferente do que ele propunha em 1896. Mas esse aspeto distintivo da sua vastíssima obra (mais de 300 títulos) releva do mesmo fenómeno - o nacionalismo - que encontrou na arte e na história os meios da sua legitimação. Como homem da Geração de 70 , alinhava com a tese de que o progresso material sem progresso moral era 
uma perversão, pois «a vida não pode ser uma estúpida página de escrituração comercial» (Viterbo, 1912: 3).

Em Esteves Pereira a história das indústrias - especialmente as dos séculos XVIII e XIX - ocupa um lugar central, tendo chegado a ser professor de Economia Política e História da Indústria. Assim, este «apaixonado pelos estudos histórico-industriais do nosso país» estava atento a um vasto conjunto de fontes do seu presente que escaparam à atenção dos restantes historiadores. Essa diferença faz de Esteves Pereira um dos primeiros, se não mesmo o primeiro historiador das atividades industriais a dar um lugar central aos aspetos de natureza económica, a atribuir um protagonismo essencial aos grandes empresários, dando importância, então rara, à organização do trabalho das fábricas, às máquinas (incluindo informação sobre marcas e proveniência), à mão de obra especializada, às matéria-primas e aos custos e mercados dos produtos. A crítica de documentos dessa natureza exigia a existência de uma memória, de uma tradição historiográfica, de mecanismos institucionais, no domínio da investigação, que ainda não existiam.

\section{A concluir}

Considerada na sua globalidade, a historiografia deste período é diversamente herdeira dos legados de Alexandre Herculano, Oliveira Martins e Teófilo Braga. Com todas as insuficiências e erros que hoje possamos apontar-lhe, foi, em muitos domínios, inovadora. O facto de alguns caminhos trilhados ou sugeridos terem permanecido no olvido durante décadas constitui um problema de capital importância, para o qual importa encontrar respostas, no âmbito da história da produção, difusão e receção das ideias, em Portugal.

Ainda que o seu património concetual fosse escasso, essa historiografia encerra, surpreendemente, um enorme desejo de compreensão do passado como condição de transformação do seu presente, de modo a fazer alinhar Portugal, descomplexadamente, com as demais nações da Europa industrializada. É evidente, na sua espantosa diversidade, não um «combate pela história", mas um combate por uma certa conceção de Estado e, como a restante historiografia, faz de Portugal o seu objeto de estudo, mesmo quando 
inventaria fábricas ou aprecia decoração cerâmica. No entanto, esses textos contêm as perplexidades, as interrogações e as respostas que foi possível dar ou encontrar nos contextos sociais e culturais que modelou e em que foi moldada. Por isso, entendo que só um espírito positivista poderia olhá-los com um sorriso condescendente nos lábios, como se esses textos se situassem numa qualquer idade "teológica" ou "metafísica" do saber histórico. A este propósito, Georges Gusdorf (1988) adverte: "os melhores livros escondem os menos bons; a última história a ser feita anula as histórias precedentes, identificando-se com a própria verdade, provavelmente com uma versão definitiva, ne varietur, de que os sábios se aproximam pouco a pouco». Importa, isso sim, conhecê-los, olhá-los dialogicamente como rica e variada produção científica e cultural, e fazer, desse trabalho de Sísifo, uma reflexão sempre inacabada sobre as condições, as realizações e natureza da historiografia portuguesa no seu conjunto.

Foi copiosa e multímoda a atividade desses investigadores, como foram múltiplas as áreas disciplinares cultivadas. No entanto, essa enorme diversidade de objetos de estudo cingia-se, grosso modo, aos séculos XV e XVI. De uma forma ou de outra, todos esses historiadores carrearam um ciclópico acervo documental para uma compreensão multifacetada dos Descobrimentos e da Expansão; abriram perspetivas para a compreensão de inúmeros enigmas, legando-nos, nessa tarefa, uma memória histórica sobre esse período que habita a historiografia atual e que devemos interrogar à luz das condicionantes e mundivivências do tempo da sua escrita. O predomínio dos estudos sobre a sociedade, as instituições, a economia e a arte dos nossos séculos XV e XVI, e sobre os Descobrimentos, constitui, pois, uma característica dominante da cultura portuguesa desde final de Oitocentos, especialmente depois da Geração de 70. Alfredo Pinheiro Marques (1991) afirma mesmo «que Herculano é exceção única na preocupação ultramarina da historiografia portuguesa».

A par da atração pelos séculos XV e XVI, e por razões diferentes, mas conexas, assiste-se a um interesse igualmente cúmplice pelo consulado pombalino. A historiografia da indústria - e de um modo geral toda a cultura portuguesa desde as duas últimas décadas do século XIX - tem uma atitude historicista perante o Marquês de Pombal. O ministro de D. José, idolatrado ou mal-amado, é mitificado por um processo tipicamente historicista, como o havia 
sido Camões. É que o mito, que "é o nada que é tudo", no dizer de Pessoa, é uma forma de dizer o indizível. Assim, as estratégias políticas e culturais de finais de Oitocentos encontravam no poder pombalino a imagem legitimadora, a referência mítica e aglutinadora de vontades, geradora de consensos para fazer face ao meta-problema da regeneração do presente «decadente». Essa mitificação assenta, pois, em pressupostos de natureza ideológica. É uma determinada conceção de Estado que a memória de Pombal releva, pelo que poderia dizer que estamos, diversamente, perante uma história mais política do que económica, industrial ou artística. Se atentarmos na sua subordinação à narrativa, cronologia e periodização (por reinados e dinastias) da historiografia política coeva, concordaremos com a justeza da apreciação.

Podemos invocar elementos de índole económica e social, como muitos e variados fenómenos de natureza ideológica e política para a compreensão dessas opções temáticas e cronológicas, pela historiografia das atividades industriais. Como diz Fernando Catroga, «a história, à boa maneira do século XIX (ou melhor, um dado período dela) é convocada para legitimar o presente-futuro através de um trabalho assente na reativação do passado, o que lhe conferia características de uma reconstituição unilateral e seletiva, porque lida à luz dos interesses do presente». Compreende-se, deste modo, porque é que a esmagadora maioria desses trabalhos de história do setor secundário são, também, textos de tribuna social e política, discursos do poder, exigindo, para a sua compreensão, uma análise cuidada, integrada no conjunto da produção cultural desse período.

Não estamos perante uma história da indústria como hoje a entendemos, mas perante textos medularmente nacionalistas, exaltadores de uma qualquer idade de ouro, seja ela configurada pela mística, ética e étnica definição de Povo - abracadabra virginal -, ou pela fabulosa e fabulada memória das grandezas do Império, ou, ainda, pela intensa, polar, mas igualmente fugaz, ação governativa de um grande homem, como Ericeira ou Pombal.

Esta historiografia vive paredes-meias com a história da arte, a etnografia, a museologia e a exegese literária. Tal situação testemunha a aversão que esses investigadores tinham ao dinheiro e a toda a cultura que a sociedade capitalista engendrava, com tudo o que tinha de equívoco e verdadeiro aos seus olhos. Essa mesma razão explica, em parte, o predomínio de estudos sobre 
certos setores, como a cerâmica decorativa, a porcelana, o vidro, o mobiliário, a tipografia, o papel, os tecidos, as rendas, a tapeçaria, a ourivesaria, e a quase ausência de trabalhos sobre minas, metalurgia, cutelaria, saboarias, curtumes, produtos químicos, etc., assim como a quase inexistência de um qualquer esboço de compreensão económica, social ou tecnológica dos setores estudados. É que os primeiros evocavam e invocavam a memória desses passados míticos, como configuravam o perfil das estratégias de diversos setores da intelectualidade para a sociedade portuguesa.

O binómio decadência/nacionalismo penetrava, como disse, todos os discursos historiográficos, conferindo-lhes unidade e sentido. Assim, é quase tautológico referir essa característica comum a toda a historiografia analisada. Contudo, é possível entrever uma evolução que importa sublinhar. Em finais de Oitocentos, apesar da "fúria patriótica» que Joaquim de Vasconcelos verberava, havia ainda uma grande abertura e disponibilidade para receber influências exteriores, os livros e as revistas circulavam; a nossa historiografia tinha construído, até então, uma memória que, de outro qualquer modo, lhe teria possibilitado a concretização de inúmeros projetos esboçados, enveredando por caminhos apontados ou questionando, até, o sentido dos percursos anteriores. Assim, se no final do século XIX era possível acompanhar as ideias da Europa culta, a partir do final da Grande Guerra, essa comunicação é crescentemente refreada; regista-se um enquistamento de cariz xenófobo. A um sistema eclético mas aberto, disponível para registar, recolher, estudar e propagandear, vai sobrepor-se um outro, mais fechado e académico. A bibliografia estrangeira citada sofre uma significativa redução. No domínio das fontes, verifica-se, igualmente, uma evolução no sentido da absolutização do documento escrito, especialmente do arquivístico, ou repetem-se os trabalhos publicados há muito.

Esta historiografia realiza uma permanente releitura da obra de Jacome Ratton, Acúrsio das Neves e Fradesso da Silveira, entre outros. Sem estes autores jamais se compreenderão os textos analisados. A par destes, Joaquim de Vasconcelos, Sousa Viterbo, Esteves Pereira e, mais tarde, José Queirós, tornam-se referência incontornável. Ficou claro que depois do «espírito da época", dos condicionalismos conjunturais, têm um papel decisivo os alinhamentos políticos e ideológicos do diversos autores. Essa historiografia 
encontra-se, assim, marcada pelas convulsões sociais, políticas e económicas do final do século XIX, e das três primeiras décadas do século passado, pela reação antiurbana provocada pelo «excesso de civilização», expressão sugestiva de Moreira Nunes, mas sente-se diversa pela marca individual desse variadíssimo painel de estudiosos, pela sua militância política, pela sua formação e ocupação profissional, pela sua origem social, pela igualmente diversa geografia de ação.

Apesar do seu indisfarçado elitismo aristocrático, esta historiografia renovou a linguagem histórica, introduzindo novos vocábulos, novas perspetivas; explorou novas fontes e, de forma inédita e inovadora, soube ler muitas outras, até aí, desconhecidas; democratizou o aprisco dos dicionários e o objeto da história, ao patentear um inusitado interesse por industriais, técnicos e trabalhadores; foi capaz de evidenciar os limites de uma história-batalha, de cariz político palaciano, mostrando um surpreendente interesse pela festa, pelos costumes, pela mulher, pela criança, pelos indigentes. Contudo, a sua maior riqueza não reside tanto naquilo que a une mas em tudo que a distingue.

Os historiadores analisados são, em número escandalosamente significativo, quase desconhecidos, não obstante alguns desses cabouqeiros terem posto a descoberto, transcrito e publicado uma apreciável e importante mole de documentos sobre os Descobrimentos. Dos mais conhecidos, porém, é muito incompleto o conhecimento da sua obra que, em alguns casos, permanece esquecida no papel amarelecido e friável dos jornais. Torna-se, assim, urgente a realização de estudos biográficos sobre esses historiadores que se aperceberam, como ninguém, do fim do mundo da Oficina e do Artesão e da emergência do mundo da Fábrica e do Operário. 


\section{HISTORIADORES DA INDÚSTRIA PORTUGUESA, 1881-1930}

\begin{tabular}{|c|c|c|c|c|}
\hline DATAS & NOMES & NATURALIDADE & FORMAÇÃO & $\begin{array}{c}\text { OBRAS } \\
\text { PUBLICADAS EM: }\end{array}$ \\
\hline $1836-1908$ & $\begin{array}{l}\text { Manuel de Melo Nunes } \\
\text { Geraldes }\end{array}$ & Covilhã? & $\begin{array}{l}\text { Engenharia } \\
\text { Mecânica na Suíça }\end{array}$ & 1913 \\
\hline $1841-1901$ & $\begin{array}{l}\text { Avelino da Silva } \\
\text { Guimarães }\end{array}$ & Guimarães & Direito & $1887-1890$ \\
\hline $1845-1910$ & $\begin{array}{l}\text { Francisco Marques } \\
\text { Sousa Viterbo }\end{array}$ & Porto & Medicina & $\begin{array}{l}\text { 1883, 1887, 1892, } \\
\text { 1892, 1896, 1896, } \\
\text { 1901, 1902, 1902, } \\
1903,1912\end{array}$ \\
\hline 1846-1912 & $\begin{array}{l}\text { Adelino António das } \\
\text { Neves de Melo }\end{array}$ & $\begin{array}{l}\text { Em viagem } \\
\text { marítima }\end{array}$ & Direito & 1886 \\
\hline 1849-1936 & $\begin{array}{l}\text { Joaquim António da } \\
\text { Fonseca Vasconcelos }\end{array}$ & Porto & $\begin{array}{l}\text { Arte, Literatura } \\
\text { e Música em } \\
\text { Hamburgo }\end{array}$ & $\begin{array}{l}\text { 1881, 1883, } 1884 \\
\text { 1985, 1891, 1901, } \\
1902,1908,1983\end{array}$ \\
\hline $1851-1927$ & Luís Augusto de Oliveira & Braga & Médico & $\begin{array}{l}\text { 1915, 1916, } 1916, \\
1918,1922\end{array}$ \\
\hline 1853-1931 & $\begin{array}{l}\text { João Augusto Marques } \\
\text { Gomes }\end{array}$ & Aveiro & Liceu? & $\begin{array}{l}\text { 1883, 1883, } 1893, \\
1913,1922,1924\end{array}$ \\
\hline $1856-1913$ & $\begin{array}{l}\text { Aníbal Gomes Ferreira } \\
\text { Cabido }\end{array}$ & Açores & Engenharia Civil & $\begin{array}{l}\text { 1911, 1911, 1911, } \\
\text { 1911, } 1917\end{array}$ \\
\hline $1856-1920$ & José Queirós & Lisboa & - & 1907 \\
\hline $1857-1944$ & $\begin{array}{l}\text { José Maria de Oliveira } \\
\text { Simões }\end{array}$ & Leiria & Engenharia & 1908 \\
\hline $1861-1921$ & $\begin{array}{l}\text { Joaquim Martins } \\
\text { Teixeira de Carvalho }\end{array}$ & Coimbra? & Medicina & 1921 \\
\hline $1865-1939$ & $\begin{array}{l}\text { D. José Maria da Silva } \\
\text { de Pessanha }\end{array}$ & - & Pintura & $\begin{array}{l}1889,1923,1924, \\
1924\end{array}$ \\
\hline $1863-1940$ & $\begin{array}{l}\text { Joaquim dos Santos } \\
\text { Barosa Sobrinho }\end{array}$ & Marinha Grande & $\begin{array}{l}\text { Vidreiro } \\
\text { autodidacta }\end{array}$ & 1912 \\
\hline $1870-1953$ & $\begin{array}{l}\text { João Teodoro Ferreira } \\
\text { Pinto Basto }\end{array}$ & - & Engenharia & 1924 \\
\hline $1872-1944$ & $\begin{array}{l}\text { João Manuel Esteves } \\
\text { Pereira }\end{array}$ & Lisboa & - & 1897, 1897, 1900 \\
\hline $1872-1944$ & $\begin{array}{l}\text { Raul Sangreman } \\
\text { Proença }\end{array}$ & $\begin{array}{l}\text { Caldas } \\
\text { da Rainha }\end{array}$ & $\begin{array}{l}\text { Ciências } \\
\text { Económicas } \\
\text { e Financeiras }\end{array}$ & $1921-22$ \\
\hline $1876-1925$ & $\begin{array}{l}\text { Fernando Emídio } \\
\text { da Silva }\end{array}$ & Lisboa & Direito & 1905, 1911, 1912 \\
\hline
\end{tabular}


historiografias portuguesa e brasileira no Seculo XX. Olhares Cruzados

HISTORIADORES DA INDÚSTRIA PORTUGUESA, 1881-1930 (continuação)

\begin{tabular}{|c|c|c|c|c|}
\hline DATAS & NOMES & NATURALIDADE & FORMAÇÃO & $\begin{array}{c}\text { OBRAS } \\
\text { PUBLICADAS EM: }\end{array}$ \\
\hline $1880-1962$ & $\begin{array}{l}\text { Gustavo de Matos } \\
\text { Sequeira }\end{array}$ & Lisboa & $\begin{array}{l}\text { Instituto Industrial } \\
\text { e Comercial de } \\
\text { Lisboa, Escola } \\
\text { Politécnica de } \\
\text { Lisboa e Curso } \\
\text { Superior de Letras }\end{array}$ & 1929 \\
\hline $1882-1944$ & $\begin{array}{l}\text { Joaquim Pedro Vitorino } \\
\text { Ribeiro }\end{array}$ & Porto & $\begin{array}{l}\text { Instituto Ind .e } \\
\text { Comercial do } \\
\text { Porto, Escola } \\
\text { Politécnica do } \\
\text { Porto e Escola } \\
\text { Médico-Cirúrgica } \\
\text { do Porto }\end{array}$ & 1930 \\
\hline $1885-1957$ & $\begin{array}{l}\text { José Caetano de Lobo } \\
\text { d'Ávila da Silva }\end{array}$ & - & Direito & 1905 \\
\hline $1887-1956$ & $\begin{array}{l}\text { João Evangelista } \\
\text { Campos Lima }\end{array}$ & Porto & Direito & 1910 \\
\hline \multirow[t]{4}{*}{ 1887-1952 } & $\begin{array}{l}\text { José Henrique } \\
\text { de Azeredo Perdigão }\end{array}$ & Viseu & Direito & 1918 \\
\hline & $\begin{array}{l}\text { Pedro Prostes da } \\
\text { Fonseca }\end{array}$ & Lisboa? & Engenharia & [1908] \\
\hline & Augusto Malheiro Dias & - & - & 1899 \\
\hline & Manuel de Araújo & - & - & 1923 \\
\hline
\end{tabular}

\section{Bibliografia sobre a indústria}

ARAÚJO, Manuel, Indústria de Braga. Notas de um jornalista, Braga, Tipografia Pax, 1923.

BAROSA, Joaquim, Memórias da Marinha Grande, 3. ${ }^{a}$ ed. ampliada [com] (introdução, notas, fixação e revisão do texto por José M. Amado Mendes), Marinha Grande, Câmara Municipal da Marinha Grande, 1993.

BASTO, João Teodoro Ferreira Pinto, A Vista Alegre. O livro do seu centenário. 1824-1924, Lisboa, Fábrica da Vista Alegre, 1924.

CABIDO, Aníbal Ferreira, Chorographia industrial do concelho de Albergaria-a-Velha, Lisboa, Imprensa Nacional, 1911.

CABIDO, Aníbal Ferreira, Chorographia industrial do concelho de Aveiro, Lisboa, Imprensa Nacional, 1911. 


\section{A primeira historiografia da Indústria Portuguesa}

CABIDO, Aníbal Ferreira, "Chorographia industrial do concelho de Ilhavo. Monografia estatística elaborada na 2. ${ }^{a}$ Circunscrição dos Serviços Technicos da Industria", in Boletim do Trabalho Industrial, $\mathrm{n} .^{\circ}$ 56, Lisboa, Imprensa Nacional, 1911.

CABIDO, Aníbal Ferreira, "Chorographia industrial do concelho d Mealhada e Vagos», Boletim do Trabalho Industrial, n. ${ }^{\circ}$ 50, Lisboa, Imprensa Nacional, 1911.

CABIDO, Aníbal Ferreira, "Corographia industrial do concelho de Espinho (distrito de Aveiro)", Boletim do Trabalho Industrial, $\mathrm{n} .^{\circ}$ 52, 1917

CARVALHO, Joaquim Martins Teixeira de, A cerâmica coimbrã no século XVI, Coimbra, Imprensa da Universidade, 1921.

COSTA, João Faustino Nazoni da, Industria de seda, Lisboa, Biblioteca de Instrução e Educação Profissional, s. d.

DIAS, Augusto Malheiro, «A industria nacional em 1891 e presentemente», A Industria Portugueza, n.os 1 e 4, 1899.

GERALDES, Manuel de Melo Nunes, Monografia sôbre a indústria do linho no distrito de Braga. Relatório de inquérito oficial à indústria do linho no distrito de Braga. Relatório de Inquérito Oficial á Indústria do Linho no Distrito de Braga, Coimbra, Imprensa da Universidade, 1913.

GOMES, João Augusto Marques e VASCONCELOS, Joaquim de, [Catálogo da] Exposição districtal de Aveiro em 1882. Reliquias da arte nacional, Aveiro, Grémio Moderno, 1883.

GOMES, João Augusto Marques, A Vista Alegre. Apontamentos para a sua história, Porto, Typ. Commercio e Industria, 1883.

GOMES, João Augusto Marques, "A fabrica da Vista Alegre", Campeão das Provincias, n. ${ }^{\circ}$ 5212, 28 de janeiro de 1893 .

GOMES, João Augusto Marques, «Museu Regional - Sala dos Barros», A Portuguesa, n. ${ }^{\circ} 37,18$ de março de 1913.

GOMES, João Augusto Marques, "Ceramica aveirense. 1487-1922", Campeão das Provincias, n. ${ }^{\circ}$ 6795 (27 de maio de 1922) ao n. 6800 (01 de julho de 1922).

GOMES, João Augusto Marques, A Vista Alegre. Memória histórica, Aveiro, Typ. Minerva Central, 1924. GONÇALVES, António Augusto, "Breve noção sobre a história da indústria cerâmica», in Charles Lepierre, Estudo chimico e technologico sobre a cerâmica moderna portuguesa, Lisboa, [s.n.], 1898. GUIMARÃES, Avelino da Silva, "Subsidios para a historia das industrias vimaranenses", Revista de Guimarães, vol. 5 (1), 1885; vol. 4 (3-4), 1887; vol. 5 (1), 1888; vol. 6(2-3), 1889; vol. 7 (2), 1890; vol. 8 (2-4), 1891; vol. 9 (1), 1892; vol. 11 (1), 1894; 13 (2), 1896.

GUIMARÃES, João Gomes de Oliveira, "Tinturaria. Apontamentos para a história das indústrias vimaranenses", Revista de Guimarães, vol. 3 (1), 1886.

LIMA, João Evangelista Campos, O movimento operario em Portugal, Lisboa, [s.n.], 1910.

MELO, Adelino António das Neves, Historia da ceramica em Coimbra (com uma biografia do autor por J. Leite de Vasconcelos), 2. ${ }^{a}$ ed., Lisboa, Portugália Editora, s. d.

MOURA, Bento Pereira de, "Apontamentos para a historia das saboarias em Portugal", Revista Universal Lisbonense, t. II, 1842-1843.

OLIVEIRA, Luís Augusto de, A extinta fábrica cerâmica de Viana, sep. dos Anais da Academia de Estudos Livres, 3. ${ }^{a}$ série, n. ${ }^{\circ}$ 1, Lisboa, Imprensa Comercial, 1915. 
OLIVEIRA, Luís Augusto de, Considerações sobre as primitivas faianças portuguesas (Faianças lisbonenses dos séculos XVI e XVIII), sep. dos Anais da Academia de Estudos Livres, $3 .^{a}$ série, n. ${ }^{\circ}$ 2, Lisboa, Imprensa Comercial, 1916.

OLIVEIRA, Luís Augusto de, Subsídios para a história da cerâmica portuguesa, Porto, Officina do Commercio do Porto, 1916.

OLIVEIRA, Luís Augusto de, Collecções de arte em Viana do Castelo. As extintas fabricas ceramicas fundadas em Coimbra e em Gaia, pelo Professor Vandelli, sep. dos Anais da Academia de Estudos Livres, $3 .^{\mathrm{a}}$ série, n. ${ }^{\circ} 3 .^{\circ}$ e $4{ }^{\circ}$, Lisboa, Imprensa Comercial, 1918.

OLIVEIRA, Luís Augusto de, A origem da faiança portugueza e as theorias dos snr. J. Martins Teixeira de Carvalho. Estudo de critica, Porto, Officina do Commercio do Porto, 1922.

ORTIGÃO, J. D. Ramalho, A Fabrica das Caldas da Rainha, Porto, Typ. Ocidental, 1891.

PERDIGÃO, José Henrique de Azeredo, "A indústria em Portugal (Notas para um inquérito)», Arquivos da Universidade de Lisboa, vol. III, 1916.

PEREIRA, João Manuel Esteves, Subsídios para a história da Indústria portuguesa, Lisboa, Guimarães \& C. ${ }^{a}$ Editores, 1979.

PESSANHA, D. José Maria da Silva de, A historia das industrias artisticas em Portugal, Lisboa, Typ. do jornal O Tempo, 1889.

PESSANHA, D. José Maria da Silva de, A porcelana em Portugal. A Fábrica da Vista Alegre (Conferência realizada em 14-06-1924, no Museu Nacional de Arte Antiga), Lisboa, Aillaud Bertrand, 1924.

PESSANHA, D. José Maria da Silva de, A porcelana em Portugal. Primeiras tentativas, Lisboa, Typ. Calçada do Cabra, 1924.

PESSANHA, D. José Maria da Silva de, O cális de ouro do Mosteiro de Alcobaça. A porcelana em Portugal (Primeiras tentativas), Coimbra, Imprensa da Universidade, 1923.

PROENÇA, Raul e ANSELMO, António, «A matéria em que se regista o passado e em que se prepara o futuro", Anais das Bibliotecas e Arquivos, vol. II (7) Julho-Outubro de 1921, p. 194-202; Idem, vol. I, (8) outubro -dezembro de 1921, p. 278-282; Idem, vol. III (10), Maio-Junho de 1922, p. 82-84. PROSTES, Pedro, Industria ceramica, Lisboa, Aillaud e Bertrand, «Biblioteca de instrucção profissional", [1908].

QUEIRÓS, José, Ceramica portugueza, Lisboa, Typ. do Annuario Commercial, 1907.

TAVEIRA, H. P., "As indústrias em Portugal", Relatório da Direcção da Associação Industrial Portuguesa, 1923, Lisboa, Emprêsa do Diario de Noticias, p. 27-38.

SEQUEIRA, Gustavo de Matos, [Introdução ao catálogo da CIP], A indústria vidreira em Portugal, Marinha Grande, 1929.

SILVA, Fernando Emídio da, O operariado português na questão social, Lisboa, 1905.

SILVA, Fernando Emídio da, Seguros mutuos, Lisboa, 1911.

SILVA, Fernando Emídio da, As greves, Coimbra, Imprensa da Universidade, 1912.

SIMÕES, José de Oliveira, «A evolução da industria portuguesa. Bosquejo historico», Notas sobre Portugal. Exposição Nacional do Rio de Janeiro em 1908. Secção portuguesa, vol. I, Lisboa, Imp. Nac., 1908.

SIMÕES, José de Oliveira, Assistencia social ás mulheres de trabalho, Lisboa, Tip. Annuario Commercial, 1909. 
VASCONCELOS, Joaquim António da Fonseca de, Historia da arte em Portugal. $1 .^{\circ}$ estudo. A pintura portugueza nos seculos XV e XVI, Porto, Typ. João E. Alves, 1881.

VASCONCELOS, Joaquim António da Fonseca de e GOMES, João Augusto Marques, [Catálogo da] Exposição districtal de Aveiro em 1882. Reliquias da arte nacional, Aveiro, Grémio Moderno, 1883.

VASCONCELOS, Joaquim António da Fonseca de, Ceramica portugueza, Porto, Typ. Elzeveriana, col. «História da Arte em Portugal (Quarto estudo)», 1884.

VASCONCELOS, Joaquim António da Fonseca de, Historia da arte em Portugal. $6 .^{\circ}$ estudo. Da architectura manuelina, Coimbra, Imprensa da Universidade, 1885.

VASCONCELOS, Joaquim António da Fonseca de, A fabrica de faianças das Caldas da Rainha, Porto, Typ. Occidental, 1891.

VASCONCELOS, Joaquim António da Fonseca de, A industria nacional dos tecidos. Legislação do seculo XV (1476-1500), Lisboa, Imprensa Nacional, 1901.

VASCONCELOS, Joaquim António da Fonseca de, Guia do Museu Municipal do Porto, Porto, Typ. Central, 1902.

VASCONCELOS, Joaquim António da Fonseca de, "A ceramica portugueza e a sua applicação decorativa” [Introdução a], Pedro Prostes, Industria ceramica, Lisboa, Aillaud e Bertrand, "Biblioteca de instrucção profissional, [1908].

VASCONCELOS, Joaquim António da Fonseca de, Indústrias portuguesas (org. e prefácio de Maria Teresa P. Viana), Instituto Português do Património Cultural, Departamento de Etnologia, col. "Estudos e materiais", n. ${ }^{\circ}$ 2, Lisboa, 1983.

VITERBO, Francisco Marques Sousa, A exposição d'arte ornamental. Notas ao catálogo, Lisboa, Imprensa Nacional, 1883.

VITERBO, Francisco Marques Sousa, A Suissa. Breves apontamentos de arqueologia militar, Lisboa, 1887.

VITERBO, Francisco Marques Sousa, "II Relojoaria", Artes e artistas em Portugal. Contribuições para a historia das artes e industrias portuguesas, Lisboa, 1892.

VITERBO, Francisco Marques Sousa, Artes e artistas em Portugal. Contribuições para a historia das artes e industrias portuguezas, Lisboa, Livraria Ferreira, 1892.

VITERBO, Francisco Marques Sousa, Arqueologia industrial portuguesa. Os moinhos, sep. do Archeologo português, vol. II, nos 8 e 9, Lisboa, Imprensa Nacional, 1896.

VITERBO, Francisco Marques Sousa, O fabrico da polvora em Portugal. Notas e documentos para a sua historia (sep. da Revista militar, t. XLVIII), Lisboa, Imprensa Universal, 1896.

VITERBO, Francisco Marques Sousa, Notas de archeologia artistica. Artes e industrias metallicas em Portugal (sep. de O archeologo portuguez, VI, nos 5-7), Imprensa Nacional, Lisboa, 1901.

VITERBO, Francisco Marques Sousa, Algumas achegas para a historia da tinturaria. Memoria apresentada á Academia das Sciencias de Lisboa, Lisboa, Typ. da Academia das Siencias de Lisboa, 1902. VITERBO, Francisco Marques Sousa, Inventores portuguezes, Coimbra, Imprensa da Universidade, 1902. VITERBO, Francisco Marques Sousa, «O papel», O Instituto. Revista Scientifica e Litteraria, vol. 50, Coimbra, Imprensa da Universidade, 1903, p. 555-563 e 631-633.

VITERBO, Francisco Marques Sousa, Cem artigos de jornal, Lisboa, Tipografia Universal, 1912.

VITORINO, Pedro, Cerâmica portuense, Gaia, Edições Apolino, 1930. 


\section{Bibliografia geral}

ANTERO, Adriano, A historia economica, vol. III: Edade Media, Porto, Typ. A. J. da Silva Teixeira, Sucessora, 1907.

CARR, E. H., Que é a História?, Lisboa, Gradiva, 1986.

CATROGA, Fernando, "Ética e sociocracia. O exemplo de Herculano na geração de 70", Studium Generale. Estudos Contemporâneos, 4: Aspectos da cultura portuguesa contemporânea, Porto, 1982.

CATROGA, Fernando, «Nacionalismo e ecumenismo. A questão ibérica na segunda metade do século XIX", Cultura, História e Filosofia, vol. IV, 1985.

CATROGA, Fernando, "Romantismo, literatura e história», in José Mattoso (dir.), História de Portugal, vol. V, Lisboa, Círculo de Leitores, 1993.

COSTA, Leonor Freire; LAINS, Pedro; MIRANDA, Susana Münch, História Económica de Portugal, 1143-2010, Lisboa, A Esfera dos Livros, 2011.

FERREIRA, Alberto, Perspectiva do romantismo português, 3. ${ }^{a}$ ed., Lisboa-Porto, Litexa, s. d.

GOMES, Joaquim Ferreira, "Dois museus industriais e comerciais criados no século XIX", Publicações do Museu da Ciência e da Técnica, n. ${ }^{\circ}$ 8, Coimbra, 1978.

GUSDORF, Georges, Da história das ciências à história do pensamento, Lisboa, Pensamento, 1988.

HERCULANO, Alexandre, Opúsculos, vol. V, Lisboa, Bertrand Editora, 1886.

LAINS, Pedro, "A indústria», in Pedro Lains e Álvaro Ferreira da Silva (org.), História Económica de Portugal, 1700-2000, vol II: O século XIX, Lisboa, Imprensa de Ciências Sociais, 2005, pp. 259-281.

MACEDO, Jorge Borges, "A 'História de Portugal nos séculos XVII e XVIII e o seu autor", in Luís Rebelo da Silva, História de Portugal nos séculos XVII e XVIII, vol. I, Lisboa, Imprensa NacionalCasa da Moeda, 1971, p. 9-130.

MARQUES, Alfredo Pinheiro, A bistoriografia dos descobrimentos portugueses, Coimbra, Livraria Minerva, 1991.

MENDES, José M. Amado, A História como Ciência. Fontes, metodologia e teorização, Coimbra Editora, 1993.

MONCADA, Luís Cabral, Subsídios para a história da filosofia do direito em Portugal (17721911), Coimbra, Coimbra Editora, 1938.

PEREIRA, José Carlos Seabra, «Tempo neo-romântico (contributo para o estudo das relações entre literatura e sociedade no primeiro quartel do século XX), Análise Social, vol. XIX (77-79), 1983.

PESSOA, Fernando, "Os Castelos", Mensagem, in Obra Poética, vol. I, Lisboa, Círculo de Leitores, 1986, p. 112.

RODRIGUES, Manuel Ferreira, A bistoriografia da indústria portuguesa, 1892-1931, Faculdade de Letras da Universidade de Coimbra (Dissertação de Mestrado), 1993.

TORGAL, Luís Reis, História e ideologia, Coimbra, Livraria Minerva, 1989.

Texto escrito conforme o Acordo Ortográfico. 